\title{
Modeling the Factors Influencing the Growth of Small and Medium Size Construction Firms in Ghana
}

\author{
Fortunatus Moo* Ephraim Elikem Ablordeppey Ibrahim Adamu Mohammed Awal Sidik \\ School of Applied Science and Technology, Department of Building Technology and Estate Management, Wa \\ Technical University, P.O Box 553, Wa-Ghana
}

\begin{abstract}
For small and medium size construction firms (SMSCF) to be well positioned to make the much needed economic impact there is the need to understand the factors that influence their growth so that policy guidelines can be formulated to enhance their effective participation in the construction industry. This study sought to identify key factors that influence the growth of SMSCF in Ghana and develop a model that could predict their growth. The study adopted a mixed research approach where preliminary interviews were conducted and subsequently surveys undertaken among SMSCF with the aid of questionnaires. Multiple regression analysis (stepwise option) was performed. An adjusted $\mathrm{R}^{2}$ value of 0.619 was realized, indicating that 61.9 per cent of growth of SMSCF in Ghana is accounted for by the findings. The findings show that lack of government support, unprofessional conduct of consultants, delayed payment for work done, high staff turnover, low educational level of contractor and poor management expertise all show negative correlation with the growth of SMSCF and thus tend to impede growth. The findings also show that absence of politics in contracting, upgrading staff, availability of capital, comparing performance with peers in the industry all show positive correlation with the growth of SMSCF and thus tend to enhance growth. The findings provide empirical evidence for adoption by policy makers and SMSCF in Ghana that could enhance growth of SMSF.
\end{abstract}

Keywords: model, Ghana, Growth, SME, SMSCF,

DOI: $10.7176 / \mathrm{JESD} / 11-12-15$

Publication date:June 30th 2020

\subsection{Introduction}

A lot of scholarly research has identified the construction industry as the backbone of most economies all over the world, as the industry provides employment and the fixed assets requirements of various sectors of the economy (Kissi et al., 2018).

Studies across many countries show that there is a positive correlation between the growth of the construction industry and aggregate output performance of those economies (Asamoah et al., 2019). In particular, these studies highlight the strong multiplier effects of construction, and the forward and backward linkages between construction and other sectors of the economy. In Ghana, the construction industry accounted for an average of $9.1 \%$ of gross domestic product (GDP) between 2001 and 2011 placing third after agriculture and government service which respectively accounted for $35.99 \%$ and $9.98 \%$, of GDP. Within the same period the average construction industry's contribution to the overall industrial sector output was $35.9 \%$ (Osei, 2013).

Studies across most developing countries suggest that the industry is numerically dominated by small and medium scale contractors, who form an average of $90 \%$ of the market (Aniekwu, 2013; Amoah et al, 2011; Laryea, 2010). Studies have however shown that the mortality/bankruptcy rate of small and medium scale contractors is high across developing economies (Bakar et al., 2012). The growth of firms results in increased profit, ability to overcome challenges in the market and increased in the share of the market. Firm size and geographical location have significant influence on the growth of businesses (Insah et al., 2013).

Ghana currently has no known documented policy towards steering the growth of the construction industry which has implication on Ghana's economic growth (Osei, 2013; Ofori, 2012). There is therefore the need for the factors that influence growth of SMEs (which numerically dominate the construction industry) to be clearly identified and monitored for improvement to enhance the growth of SMEs in the construction industry. The main objective of the study is to identify key factors that influence the growth of SMSCF in Ghana and develop a model that could predict their growth.

\subsection{Literature Review of Factors Influencing Growth of Firms}

The determinants of a firm's growth vary dependent on size, prevailing economic conditions and the geographical location within which the firm operates (Obeng et al., 2014). Generally, the factors that determine firm growth relate to entrepreneurial, inter-firm characteristics and external factors. Factors relating to the entrepreneur such as sex, age, level of education, previous work experience, management skill, economic background and marital status determine the growth of SMEs (Kulemeka et al., 2015). Male headed firms grow faster than that of femaleheaded (Windapo, 2017). Growth of SMEs improves with increasing education. Some studies (Windapo, 2017) reported that a firm with more years of work experience typically has faster-growth than their counterpart. Start- 
up capital of a given firm has significant positive effect on the growth of MSEs (Coleman et al., 2016).

The overall growth of businesses is influenced by macro-economic policies of government and external factors such as access to credit, infrastructure, market, working place, technology, social services and other legal and regulatory frameworks (Osei, 2013). Yankah et al. (2016) argued that growth of SMEs is affected by inter firm related factors like linkage, network, and competition. With regard to the sector growth relationship, firms engaged in manufacturing and service sector grow faster than their counterparts in other sectors (Kulemeka et al. 2015; Arthur-Aidoo et al., 2016). Firms with growth potential tend to recoil due to the difficulties they face in accessing external sources of funding which are critical ingredients for business growth (Hove, 2016).

Artz et al. (2016) argued that good management expertise, developing skills of workers, good quality control of products, market specialization and strong capital base are deemed as important growth factors to the company. Also determinants of firm growth vary from one industrial sector to the other and between small and large businesses.

Research has identified several factors peculiar to the construction industry that impede the growth of SMEs in the industry in developing countries. In Ghana, the congenital payment delay particularly by the major client (Government) in the industry post serious cash flow challenges to contractors particularly SMSCF and this impact negatively on the growth of their businesses (Amoah et al., 2011).

The indicators for business growth have included returns from sales, volume of production, market share, returns on investment, employee size, and number of production/production/operation outlets and extent of geographical coverage (Ofori, 2000). A firm's growth can be measured in terms of its capital investment, value of assets, market capitalization, economic value added, elements or outputs sales, revenues, profit (Bakar et al., 2012). In the construction industry, a contractor who moves from one financial class to the next higher class is assumed to have experienced growth

\subsection{Definitions of Firm Growth and Growth Theories}

Growth is defined in terms of the value addition, quality of product, increase in production output, share of market, employee size, goodwill of customers, geographical spread etc (Gupta et al., 2013). Insah et al (2013) posited that the level of revenue generated and volume of production over a given period gives a quantitative measure of growth of a firm. Theories on the growth of firms have been discussed extensively in the literature (Choi et al., 2019; Geroski, 1999). Geroski (1999) discussed the model of optimum firm size, the growth stage model, model with Penrose effects, and models of organizational capabilities. The second model suggests that firm growth is a stochastic process and is subjected to a cumulative random shock. The third model describes firm growth as a sequence of grow stages. Penrose (1959) argues that enterprises have a limit to which they can grow but there exist no limit to the size of the enterprise. Geroski (1999) building on Penrose's work, posited that firm growth is a development process which entails the building up of skills and competencies that are unique to the firm which can be learned over a period through mutual sharing which is beneficial in extending the firm's productive opportunities. Classification of construction firms is based on the resource holding capacity such as human, financial, equipment resources of the enterprise (Eyiah, 2004). Construction firm gain competitive urge over their peers depending on their ability to manage resources, both internal resources including political connection and mitigate the challenges that confront businesses in the industry (Ameyaw et al., 2013; Islam et al., 2011; Jafaar\& Abdul-Aziz, 2005).

\subsection{Research methods}

Where variables are unknown with very scanty theory base about a subject under study qualitative study can help identify what is important to be studied (Leedy \& Jeanne, 2005). Thus as a prelude to this study qualitative inquiry was conducted with SMSCF in Ghana as key participants; all aimed at identifying growth variables that are peculiar to the construction industry, particularly. The findings from the qualitative inquiry (reported elsewhere) and the literature review formed the theoretical framework (Fig. 1) for this study. The mixed approach ensures a more holistic inquiry in scrutinizing a research problem (Creswell, 2007).

Survey questionnaire were used as instrument for data collection. Section A of the questionnaire sought to establish the demographic features of the respondents. The main crust for developing a model for the growth of SMSCF is the identification of variables that influence growth (independent variables) and then growth (dependent variable) (Baker et al, 2012). Sections B sought to establish independent variables whilst C represented the dependent variable. In developing the questionnaire, the issues emerging from the qualitative interview of a sample of the respondents to the questionnaire as well as the independent expert opinions of construction industry consultants in the research area were factored into the development of the questionnaire. Additionally, previous studies adopted similar questionnaire techniques which proved very successful (Aigbavboa \& Thwala, 2014; Baker, et al., 2012; Abor\&Quartey, 2010). Also pilot testing the questionnaire was another way to ensure the validity of the questionnaire. The first phase entailed interviewing managers of small and medium scale contractors (SMSCF) as well as construction industry consultants who operate within the research area. The 
second phase involved administering structured questionnaire to SMSCF in the research area.

Indeed key independent variables for business growth of SMSFs were established from the two sources and they formed the bases for designing closed ended questionnaire for the collection of quantitative data from SMSFs.

It is difficult to find an accurate and up-to-date data of registered contractors in developing countries due to poor documentation of the agencies responsible for contractors' registration and the high attrition rate of construction business in developing countries. Thus the sampling frame for this study was established from a collation of registered lists of contractors that construction industry consultants have worked with for the past five years and beyond. Since government remains the largest employer in the construction industry, this technique was adopted in order to establish a credible sampling frame to work with. In all, a total of 532 SMSCFs who operate across the five regions in northern Ghana for the past five years formed the sampling frame. This study applied the well acclaimed Kish formula for the determination of the sample size for the quantitative data collection (Kish, 1965).

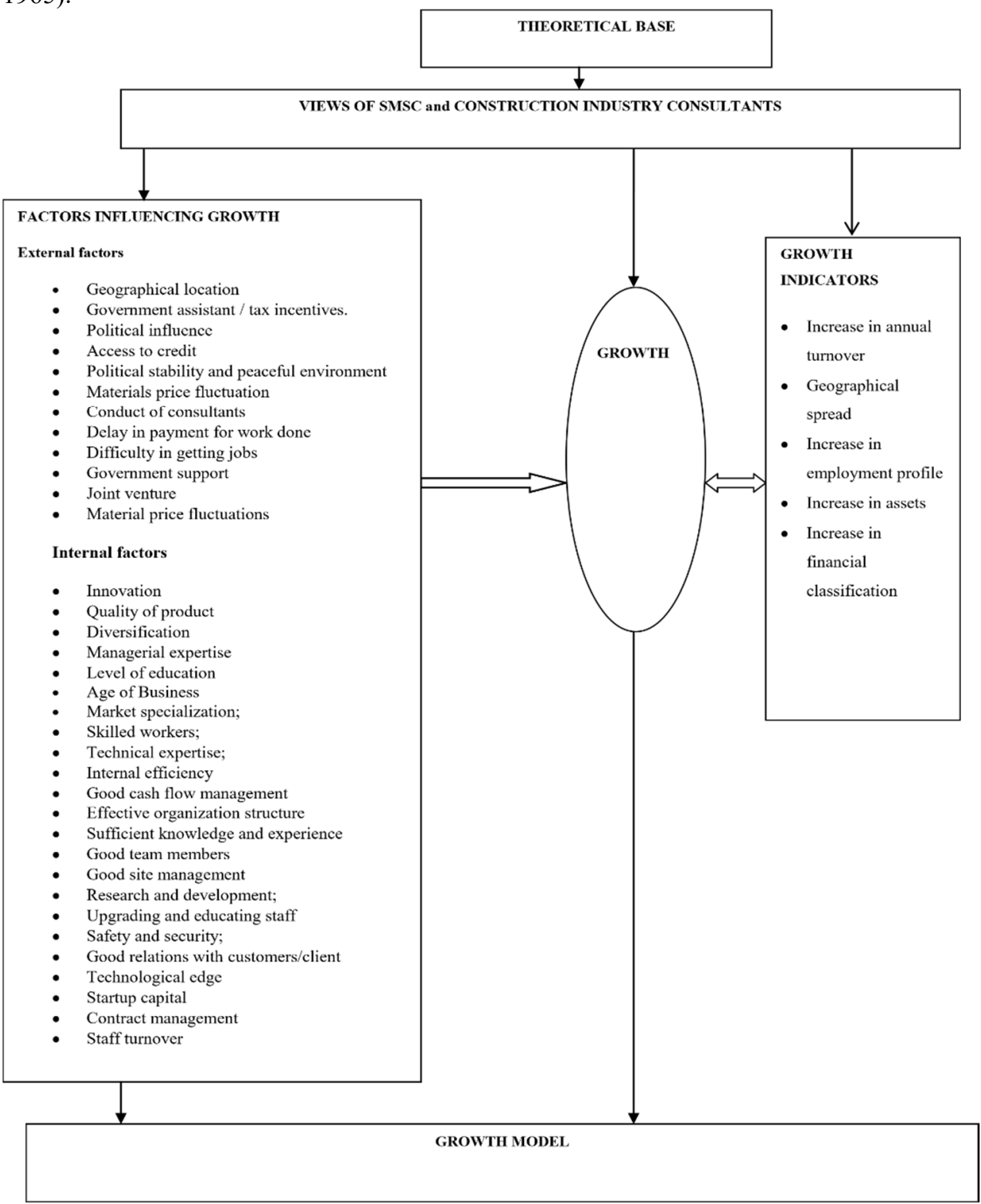

Figure 1.1: Theoretical Framework (Source: Researchers' construct, 2020)

\subsection{DATA ANALYSIS}

\subsection{Demographics}

In all one hundred and one (101) questionnaires were retrieved from respondents (out of 210). Employment profile, assets level and annual turnover are indicators of growth (Bakar et al., 2012). Also an increase in the financial classification of a firm from class D4K4 to D3K3 is a manifestation of growth (Eyiah, 2004). Only 25\%, 18\% and 
$22 \%$ have increased their employment profile, assets base and annual turnover respectively over the last ten years. This means that more than $70 \%$ of the respondents have not experienced any growth in their business over the period. This view is further reinforced by the fact that over the same period only $20 \%$ of the respondents have been able to move from financial class D4K4 to D3K3, leaving about $80 \%$ who have remained on the same class over the period.

Contractors that move from the lower financial class of D4K4 to class D3K3 has experienced some amount of growth as there is significant difference in capital requirements for the two classes (Eyiah, 2004). 64.56\% of the respondents were D3K3 contractors with the D4K4 contractors constituting 35.64\%. Approximately, 20 percent of contractors who initially registered as class D4K4 contractors have been able to move to class D3K3 over the years indicating some level of growth.

More than $60 \%$ of the respondents are less than ten years in the construction business with $38.61 \%$ of them particularly being under five years. Less than $30 \%$ of the respondents are over 10 years with $6.93 \%$ of them specifically being over sixteen years in business. This means that majority of the respondents could suffer the newness liability in business growth (Damoah, 2013; Acquaah \& Eshun, 2010). Virtually all respondents (100) of the business were sole proprietors with only one being a limited liability. Also 100 of the respondents were owners (directors) of the businesses with only one respondents being a foreman. This means that the responses to the questionnaire by and large came from the right caliber of persons with the right information about their businesses. All the 101 respondents had less than 5 full time employees and over $80 \%$ of them engage less than 20 part-time employees, with $18.81 \%$ specifically engaging over 16 full time employees. All respondents are hired by private individuals and the District Assemblies whose projects are mostly financed by the District Assembly common fund. Notwithstanding the private client participation in construction business the research area, the level of participation is lower than what happens in southern Ghana due to the high income inequality between north and southern Ghana

$53 \%$ of the respondents have successfully completed and handed over less than 5 projects in the last ten years with $16 \%$ of each respondents completing and handing over more than 10 projects in the last ten years. The high number of respondents who completed less than five projects in the past ten years goes to reinforce the difficulty encountered in getting jobs as revealed in the preliminary interview. $15.84 \%$ of respondents have abandoned a total of 16 projects in the past due to payment challenges by the client. A total of 91 projects were under construction by $50.49 \%(51)$ of the respondents. This means that $49.51 \%(50)$ of the respondents were idle at the time. This further reinforces the difficulty in access jobs as revealed in the preliminary interview.

\subsection{Interpretation of Multiple Regression Result}

The analysis of the independent variables using the stepwise elimination option of SPSS generated a number of data tables and figures that describe the relationship between the independent variables and the dependent variable. The stepwise elimination method add and eliminate variables based on the mathematical criteria of $\mathrm{P}<0.05$ for entry (Field, 2009). These are now interpreted in the ensuing sections.

\subsubsection{Descriptive Statistics}

Table 4.1 presents the mean and standard deviations of each variable that passed the stepwise elimination mathematical criterion of $\mathrm{P}<0.05$ for entry. From the table the mean growth of SMSCF is 2.6337 which is below average confirming the analysis of growth in section 1.4.1.1. The notations in brackets represent the codes of the identified variables. GC denotes a variable which appear as an impediment to growth while GD denotes variable which enhance growth with GRW denoting growth of SMSCF which is the dependent variable.

\section{Table 4.1 Descriptive Statistics}

\begin{tabular}{|l|l|l|l|}
\hline \multicolumn{1}{|c|}{ Variables } & Mean & Std. Deviation & $\mathrm{N}$ \\
Growth & 2.6337 & .82125 & 101 \\
Lack of government support $\left(\mathrm{GC}_{1}\right)$ & 4.0792 & .75741 & 101 \\
Unprofessional conduct of consultants $\left(\mathrm{GC}_{2}\right)$ & 2.4356 & 1.04322 & 101 \\
Delayed payment for work done $\left(\mathrm{GC}_{3}\right)$ & 4.4851 & .76960 & 101 \\
High staff turnover $(\mathrm{GC})$ & 2.8020 & 1.02000 & 101 \\
Low education level of contractor $\left(\mathrm{GC}_{5}\right)$ & 2.2079 & 1.22733 & 101 \\
Poor managerial expertise $(\mathrm{GC} 6)$ & 3.2574 & 1.47413 & 101 \\
Absence of politics in contracting $\left(\mathrm{GD}_{1}\right)$ & 3.7129 & 1.32918 & 101 \\
Upgrading staff $\left(\mathrm{GD}_{2}\right)$ & 2.6535 & 1.13521 & 101 \\
Availability of capital $\left(\mathrm{GD}_{3}\right)$ & 4.0198 & .83642 & 101 \\
Compare with peers in the industry $\left(\mathrm{GD}_{4}\right)$ & 3.1188 & .85191 & 101 \\
\hline
\end{tabular}

Table 4.2 gives a useful summary of the data. First it shows the Pearson's correlation coefficient between each pair of variables. For instance it shows that low level of education shows a negative correlation -0.211 with 
growth of SMSC and it is significant at $\mathrm{P}<0.05$ as shown in the second rows of the tables labeled Sig. (1-tailed).The table also give information of the number of cases contributing to the correlation.

Table 4.2 Correlations

\begin{tabular}{|c|c|c|c|c|c|c|c|c|c|c|c|c|}
\hline & & Growth & GC1 & GC2 & GC3 & GC4 & GC5 & GC6 & GD1 & GD2 & GD3 & GD4 \\
\hline Pearson & GRW & 1.000 & -.162 & -.106 & $-.157 \mid$ &.-115 & $-.211 \mid$ & -.136 & .363 & .202 & .244 & .149 \\
\hline \multirow[t]{10}{*}{ Correlation } & GC1 & -.162 & 1.000 & -.120 & .500 & -.316 & -.125 & -.404 & -.067 & -.038 & .471 & -.185 \\
\hline & GC2 & -.106 & -.120 & 1.000 & -.179 & -.050 & .405 & .063 & .069 & .171 & -.021 & .121 \\
\hline & GC3 & -.157 & .500 & -.179 & 1.000 & -.080 & .040 & -.173 & -.097 & -.069 & .389 & -.287 \\
\hline & GC4 & -.115 & -.316 & -.050 & -.080 & 1.000 & .225 & .267 & .238 & .122 & -.101 & .108 \\
\hline & GC5 & -.211 & -.125 & .405 & .040 & .225 & 1.000 & .241 & .141 & .411 & -.053 & .340 \\
\hline & GC6 & -.136 & -.404 & .063 & -.173 & .267 & .241 & 1.000 & .278 & .394 & -.296 & .015 \\
\hline & GD1 & .363 & -.067 & .069 & -.097 & .238 & .141 & .278 & 1.000 & .059 & -.085 & .004 \\
\hline & GD2 & .202 & -.038 & .171 & -.069 & .122 & .411 & .394 & .059 & 1.000 & -.109 & .260 \\
\hline & GD3 & 244 & .471 & -.021 & .389 & -.101 & -.053 & -.296 & -.085 & -.109 & 1.000 & .095 \\
\hline & GD4 & .149 & -.185 & .121 & -.287 & .108 & .340 & .015 & .004 & .260 & .095 & 1.000 \\
\hline \multicolumn{2}{|c|}{ Sig. (1-tailed) } & & & & & & & & & & & \\
\hline & GRW & $.053 \mid$ & & & & & & & & & & \\
\hline & GC1 & .145| & |116 & & & & & & & & & \\
\hline & $\mathrm{GC} 3$ & .058 & .000 & .037 &. & & & & & & & \\
\hline & GC4 & $.125 \mid$ & (001| & .311 & .213 & & & & & & & \\
\hline & GC5 & .017 & .106 & .000 & .344 & .012 & & & & & & \\
\hline & $\begin{array}{l}\text { GC6 } \\
\text { GD1 }\end{array}$ & 087 & .000 & .266 & .042 & .003 & .008 & & & & & \\
\hline & GD2 & .000 & .254 & .245 & .167 & .008 & .080 & .002 & & & & \\
\hline & GD3 & .021 & .355 & .044 & .247 & .113 & .000 & .000 & .278 & & & \\
\hline & GD4 & .007 & .000 & .416 & .000 & .158 & .300 & .001 & .200 & .140 & & \\
\hline & & .069 & .032 & .114 & .002 & .141 & .000 & .440 & .484 & .004 & .173 & \\
\hline \multirow[t]{11}{*}{ N } & & 101 & 101| & 101 & 101 & 101 & 101 & 101 & 101 & 101 & 101| & 101 \\
\hline & GRW & 101 & 101 & 101 & 101 & 101 & 101 & 101 & 101 & 101 & 101 & 101 \\
\hline & $\begin{array}{l}\mathrm{GCl} \\
\mathrm{GC} 2\end{array}$ & $101 \mid$ & $101 \mid$ & 101 & 101 & 101 & 101 & 101 & 101 & 101 & 101 & 101 \\
\hline & $\mathrm{GC} 3$ & 101 & 101| & 101 & 101 & 101 & 101 & 101 & 101 & 101 & 101 & 101 \\
\hline & GC4 & 101 & 101 & 101 & 101 & 101 & 101 & 101 & 101 & 101 & 101 & 101 \\
\hline & GC5 & 101 & 101 & 101 & 101 & 101 & 101 & 101 & 101 & 101 & 101 & 101 \\
\hline & GC6 & $101 \mid$ & 101| & 101 & 101 & 101 & 101 & 101 & 101 & 101 & 101 & 101 \\
\hline & GD2 & 101 & 101 & 101 & 101 & 101 & 101 & 101 & 101 & 101 & 101 & 101 \\
\hline & GD3 & 101 & 101| & 101 & 101 & 101 & 101 & 101 & 101 & 101 & 101 & 101 \\
\hline & GD4 & 101 & 101 & 101 & 101 & 101 & 101 & 101 & 101 & 101 & 101 & 101 \\
\hline & & $101 \mid$ & 101 & 101 & 101 & 101 & 101 & 101 & 101 & 101 & 101 & 101 \\
\hline
\end{tabular}

Table 4.3: Model Summary

\begin{tabular}{|c|c|c|c|c|c|c|c|c|c|c|}
\hline \multirow[b]{2}{*}{ Model } & \multirow[b]{2}{*}{$\mathrm{R}$} & \multirow[b]{2}{*}{$\begin{array}{c}\mathrm{R} \\
\text { Square }\end{array}$} & \multirow[b]{2}{*}{$\begin{array}{l}\text { Adjusted R } \\
\text { Square }\end{array}$} & \multirow{2}{*}{$\begin{array}{l}\text { Std. Error of } \\
\text { the } \\
\text { Estimate }\end{array}$} & \multicolumn{5}{|c|}{ Change Statistics } & \multirow[b]{2}{*}{$\begin{array}{l}\text { Durbin- } \\
\text { Watson }\end{array}$} \\
\hline & & & & & $\begin{array}{c}\text { R Square } \\
\text { Change }\end{array}$ & $\begin{array}{c}\mathrm{F} \\
\text { Change }\end{array}$ & df1 & $\mathrm{df} 2$ & $\begin{array}{c}\text { Sig. F } \\
\text { Change }\end{array}$ & \\
\hline 1 & $.435^{\mathrm{a}}$ & .189 & .181 & .74334 & .189 & 23.063 & 1 & 99 & .000 & \\
\hline 2 & $.523^{\mathrm{b}}$ & .274 & .259 & .70684 & .085 & 11.488 & 1 & 98 & $.001 \mid$ & \\
\hline 3 & $.568 \mathrm{c}$ & .322 & .302 & .68635 & .048 & 6.937 & 1 & 97 & .010 & \\
\hline 4 & $.611^{\mathrm{d}}$ & .373 & .347 & .66351| & $.051 \mid$ & 7.793 & 1 & 96 & .006 & \\
\hline 5 & $.654^{\mathrm{e}}$ & .427 & .397| & .63756 & .054 & 8.973 & 1 & 95 & $.003 \mid$ & \\
\hline 6 & $.676^{\mathrm{f}}$ & .457 & .422 & .62413 & .030 & 5.133 & 1 & 94 & .026 & \\
\hline 7 & $.699^{\mathrm{g}}$ & .489 & .451 & .60874 & .032 & 5.814 & 1 & 93 & .018 & \\
\hline 8 & $.721^{\mathrm{h}}$ & .520 & 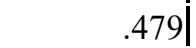 & .59290 & .031 & 6.036 & 1 & 92 & .016 & \\
\hline 9 & $.740^{\mathrm{i}}$ & .548 & .503 & .57877 & .028 & 5.545 & 1 & 91 & .021 & \\
\hline 10 & $.756^{\mathrm{j}}$ & .571 & .523 & .56692 & .023 & 4.844 & 1 & 90 & .030 & \\
\hline 11 & $.747 \mathrm{k}$ & .559 & .515 & .57194 & .012 & 2.617 & 1 & 90 & |109. & \\
\hline 12 & $.771^{1}$ & .595 & .550 & |55109. & .036 & 8.015 & 1 & 90 & .006 & \\
\hline 13 & $.802^{\mathrm{m}}$ & .644 & .600| & 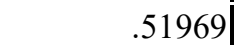 & |049| & 12.204 & 1 & 89 & .001 & \\
\hline 14 & $.801^{\mathrm{n}}$ & .642 & .602 & .51804 & .002 & .428 & 1 & 89 & .515 & \\
\hline 15 & $.799^{\circ}$ & .638 & $.602 \mid$ & .51800 & .004 & .984 & 1 & 90 & .324 & \\
\hline 16 & $.811^{\mathrm{p}}$ & .657 & 619 & .50673 & .019 & 5.089 & 1 & 90 & .026 & 1.588 \\
\hline
\end{tabular}


b. Predictors: (Constant), Client satisfaction, No government support

c. Predictors: (Constant), Client satisfaction, No government support, No politics in contracting

d. Predictors: (Constant), Client satisfaction, No government support, No politics in contracting, Joint venture

e. Predictors: (Constant), Client satisfaction, No government support, No politics in contracting, Joint venture, Poor mgt expert

f. Predictors: (Constant), Client satisfaction, No government support, No politics in contracting, Joint venture, Poor mgt expert, Education level

g. Predictors: (Constant), Client satisfaction, No government support, No politics in contracting, Joint venture, Poor mgt expert, Education level,

Availiability of capital

h. Predictors: (Constant), Client satisfaction, No government support, No politics in contracting, Joint venture, Poor mgt expert, Education level,

Availiability of capital, Unprofessional conduct

i. Predictors: (Constant), Client satisfaction, No government support, No politics in contracting, Joint venture, Poor mgt expert, Education level,

Availiability of capital, Unprofessional conduct, Staff turnover

j. Predictors: (Constant), Client satisfaction, No government support, No politics in contracting, Joint venture, Poor mgt expert, Education level,

Availiability of capital, Unprofessional conduct, Staff turnover, Compare with peers

k. Predictors: (Constant), Client satisfaction, No politics in contracting, Joint venture, Poor mgt expert, Education level, Availiability of capital,

Unprofessional conduct, Staff turnover, Compare with peers

1. Predictors: (Constant), Client satisfaction, No politics in contracting, Joint venture, Poor mgt expert, Education level, Availiability of capital,

Unprofessional conduct, Staff turnover, Compare with peers, Upgrading staff

m. Predictors: (Constant), Client satisfaction, No politics in contracting, Joint venture, Poor mgt expert, Education level, Availiability of capital,

Unprofessional conduct, Staff turnover, Compare with peers, Upgrading staff, Delayed payment

n. Predictors: (Constant), No politics in contracting, Joint venture, Poor mgt expert, Education level, Availability of capital, Unprofessional conduct, Staff turnover, Compare with peers, Upgrading staff, Delayed payment

o. Predictors: (Constant), No politics in contracting, Poor mgt expert, Education level, Availability of capital, Unprofessional conduct, Staff turnover, Compare with peers, Upgrading staff, Delayed payment

p. Predictors: (Constant), No politics in contracting, Poor mgt expert, Education level, Availability of capital, Unprofessional conduct, Staff turnover, Compare with peers, Upgrading staff, Delayed payment, No government support q. Dependent Variable: Growth

\subsubsection{THE MODELS SUMMARY}

Table 4.3 provides the model summary for the regression analysis. It is significant to note from the table that 16 models were produced, but only the $16^{\text {th }}$ model was selected since it was the only one with the optimum number of variables that met the set criteria (Field, 2009). The column labeled $\mathrm{R}$ is a measure of the correlation between the observed values and the predicted value of the criterion variable. Thus from table $4.3, \mathrm{R}$ for the selected model is 0.811 which is a measure of the correlation between the selected variables for the model (GC1, GC2, GC3, GC4, GC5, GC6, GD1, GD2 and GD3 and GD4) and the dependent variable (GRW) (see table 4.2). The R Square $\left(\mathrm{R}^{2}\right)$ is the square of this measure of correlation and indicates the proportion of the variance in the criterion variable which is accounted for by the model, in this case the proportion of variance in growth accounted for by the set of predicator variables (Brace et al., 2009). In essence, this is a measure of how good a prediction of the criterion variable can be made by knowing the predictor variables. However, R square tends to somewhat over-estimate the success of the model when applied to the real world, so an Adjusted R Square value is calculated which takes into account the number of variables in the model and the number of observations (participants) the model is based on. This Adjusted R Square value gives the most useful measure of the success of the model and is expected to be as close as possible to the R square (Brace et al., 2009; Field, 2009; Leech et al., 2005. Thus in table 4.3, $\mathrm{R}^{2}$ for the selected model is 0.657 and corresponding adjusted $\mathrm{R}^{2}$ value is 0.619 . This means that the selected predicator variables in the model account for $61.9 \%$ of variance (increase or decrease) in the growth of SMSCF. The change statistics columns show whether the change in $\mathrm{R}^{2}$ is significant. Also it shows the difference made by adding new predicators to the model. Finally, the Durbin-Watson statistics shown at the extreme end of table 4.3 informs whether the assumptions of the independent errors are well founded. Field (2009) posited that the ideal values for DurbinWatson statistics ranges between 1 and 3. Meaning any value less than 1 or greater than 3 should be a cause for alarm. Fortunately however, table 4.3 gives DurbinWatson value of 1.588 which falls within the two extremes. 


\subsubsection{Model Parameters}

Table4.4: Coefficients ${ }^{\mathrm{a}}$

\begin{tabular}{|c|c|c|c|c|c|c|c|c|c|c|c|c|}
\hline Model & $\begin{array}{r}\text { Unstar } \\
\text { Coef }\end{array}$ & $\begin{array}{l}\text { ndardized } \\
\text { fficients } \\
\text { Std. } \\
\text { Error }\end{array}$ & $\begin{array}{c}\text { Standardized } \\
\text { Coefficients } \\
\text { Beta }\end{array}$ & $\mathrm{T}$ & Sig. & \multicolumn{2}{|c|}{\begin{tabular}{|c|c|}
\multicolumn{2}{|c|}{$95.0 \%$} \\
Confidence \\
Interval for B \\
Lower & Upper \\
Bound & Bound \\
\end{tabular}} & \multicolumn{3}{|c|}{ Correlations } & \multicolumn{2}{|c|}{$\begin{array}{c}\text { Collinearity } \\
\text { Statistics }\end{array}$} \\
\hline $\begin{array}{l}16 \\
(\text { Constant })\end{array}$ & -.151 & .595 & & -.253 & .801 & $-\overline{1.333}$ & 1.032 & & & & & \\
\hline $\mathrm{GC} 1$ & -.213 & .094 & -.197 & -2.256 & .026 & -.401 & -.025 & -.162 & -.231 & $|-.139|$ & .502 & | 1.993 \\
\hline GD1 & .271 & .041 & .438 & 6.573 & .000 & .353 & .189 & .363 & .569 & .406 & .856 & $\mid 1.168$ \\
\hline GC6 & -.258 & .044 & -.464 & -5.841 & .000 & -.171 &.-346 & -.136 & -.524 & -.360 & .604 & 1.657 \\
\hline GC5 & -.333 & .055 & -.498 & $\mid-6.088$ & .000 & -.442 & -.225 & -.211 & -.540 & $|-.376|$ & .569 & 1.758 \\
\hline GD3 & .210 & .075 & .214 & $2.807 \mid$ & .006 & .061 & .359 & .244 & .284 & .173 & .654 & 1.530 \\
\hline $\mathrm{GC} 2$ & -.298 & .056 & -.378 & $|-5.297|$ & .000 & -.186 & -.410 & -.106 & -.487 & $|-.327|$ & .746 & 1.340 \\
\hline GC4 & -.172 & .056 & -.214 & $\mid-3.071$ & .003 & -.061 & -.284 & -.115 & -.308 & $|-.190|$ & .784 & 1.275 \\
\hline GD4 & .367 & .073 & .381 & \begin{tabular}{|l|}
5.052 \\
\end{tabular} & .000 & .223 & .511 & .149 & .470 & $|.312|$ & .671 & $\mid 1.491$ \\
\hline GD2 & 217 & .055 & .300 & 3.961 & .000 & .326 & .108 & .202 & .385 & $|.244|$ & .663 & 1.508 \\
\hline $\mathrm{GC} 3$ & -.431 & .086 & -.403 & $\mid-4.979$ & .000 & -.259 & -.602 & -.157 & -.465 & -.307 & .580 & 1.725 \\
\hline
\end{tabular}

Table 4.4 presents the estimates for $\mathrm{B}$ and $\beta$-values which represent the individual contribution of each predicator variable to the model. There is no agreement amongst researchers as to whether the $\mathrm{B}$ or $\beta$ values should be used for the regression equation. Whilst some argue for the B others argue for $\beta$ (Ahadzie, 2007; Bell, 2005; Burns \& Grove, 1997). However there is a consensus that when comparing the partial impact of the individual independent variables on the dependent variable the $\beta$ is preferred (Linneman, 2010). Even though some researchers use the values of $B$ in formulating multiple regression equation, they do not have a common benchmark for comparison since the value of the B depends on how the variables are coded and they indicate the direction and number of units (as coded) of change in the dependent variable due to a one unit change in each independent variable (Linneman, 2010). A positive B-value represents a positive relationship between that particular predicator and the outcome whiles a negative value shows a negative relationship. The $\beta$ values indicate the relative influence of the variables in comparable (standard deviation) units. According to Jaccard\&Turrisi (2003) when variables are measured in concrete units ( e.g dollars, years, or percentages), B is relatively easy to interpret because it expresses the potential effects of the independent variables on the dependent variable in their original units of measurement. They argued that the meaning of $\beta$ is not intuitively clear and cannot be interpreted concretely, but when independent variables are measured in different units only $\beta$ allow for a direct comparison of the effects of different independent variables on the dependent variables. Thus in this study, the $\beta$ values (Standardized coefficients) are used as coefficients in the regression equation and this makes it easy for direct comparison of the individual predicators to the model. However the $\mathrm{B}$ values are used in interpreting the direction of the relationship between the predicators and the criterion variables (Ahadzie, 2007)

Also worthy of mention is the coefficient tables is the Y-intercept or constant value. This value gives growth of SMSCF even when the predicator variables are absent or when they all have zero values. Thus there is the need to effectively bring in these predicator variables to improve upon growth. From table 4.4 the $\beta$ values of lack of government support $\left(G C_{l}\right)$ is -0.197 which means that holding all the other predicators constant, a unit change in $G C_{l}$ will result in a change in Growth by -0.197 . Similarly, it is clear from the table that the standardized partial regression coefficients of the rest of the predicator variables are unprofessional conduct of consultants (GC, $C_{2}$, 0.378), Delayed payment for work done $\left(G C_{3}, 0.403\right)$, High staff turnover $\left(G C_{4},-0.214\right)$, Low educational level of contractor $\left(G C_{5},-0.498\right)$, Poor management expertise $\left(G C_{6},-0.464\right)$, Absence of politics in contracting $\left(G D_{1}\right.$, 0.438), Upgrading staff $\left(G D_{2}, 0.300\right)$, Availability of capital $\left(G D_{3}, 0.214\right)$, Compare performance with peers in the industry $\left(G D_{4}, 0.381\right)$. These partial regression coefficients means that, holding all the other variables constant, a unit change in any one variable will results in a corresponding change in growth equal to the partial regression coefficient of that variable (Field, 2009.) Having established the parameters of the model is now stated as equation 4.1 below.

$\mathrm{Y}_{\mathrm{GRW}}=-0.151-0.197 \mathrm{GC}_{1}+0.438 \mathrm{GD}_{1}-0.464 \mathrm{GC}_{6}-0.498 \mathrm{GC}_{5}+0.214 \mathrm{GD}_{3}-0.378 \mathrm{GC}_{2}-$ 


\subsection{Discussion of results}

Delayed payment for work done'(GC3) post a big challenge to their growth. From table 4.14 and equation 4.1, GC3 has a $\beta$ value of -0.403 showing a negative correlation with growth. As GC3 increases in absolute value, growth decreases in absolute value. This means that a unit change in GC3 will result in a change in GRW by 0.403 standardized units. Indeed the issue of delayed payment particularly for government projects has consistently been quoted as a bane to the performance, growth and development of the construction industry in developing countries and Ghana cannot be an exception (Amoah et al., 2011; Laryea, 2010; Eyiah and Cook, 2003). This problem is further exacerbated by the difficulty faced by SMSC contractors in getting bank loans and other forms of credit (Eyiah\& Cook, 2003).

According to (Nawaz \&Ikram, 2013) the construction industry is tainted with unethical conduct and practices. Poor bid analysis, absence of transparency in bid selection process and general noncompliance with ethic policies constitute unprofessional conduct. Corruption in the award of contracts has been identified as a canker and indeed a bane to the economy of most nations (Ameyaw\& Mensah, 2013). Respondents revealed at the interview stage that during bidding it is common practice for consultants to be the one to price the bids for all bidders at a fee and yet be the one to determine successful bidders. The consultants also contend that they are in most cases given specific instructions to award specific projects to their chosen contractors. This in the words of some of the consultants' stifles professionalism in the discharge of our duties' Thus under the circumstance transparency and professionalism are compromised at the contract award stage.

Muogbo (2013) posited that an organization key competency and competitive advantage is its human capital. Similarly, Mohammed \&Obeleagu-Nzelibe (2014) and Arokiasamy (2013) posited that recruiting, training, motivating and retaining highly skilled competent human resource has become a thorny issue for organizations to remain competitive in this globalized world economy. Labour turnover or employees leaving an organization presents numerous challenges than benefits to organizational management (Kuria et al., 2012). For instance Bilau et al.(2015) posited that employee's turnover has had a negative impact on the growth and development of small and medium sized construction firms as the services of the lost employees are no longer available to be utilized by the firm after putting in their resources in training them.

In the current study, it was observed that as high as $47 \%$ of respondents were idling at the time the research data were being collected. The situation reinforces the reported general difficulty local contractors face in accessing jobs in the industry (Laryea, 2010). Under the circumstances, it makes economic sense for its employees to leave to find jobs elsewhere. The delayed payment for work done by contractors have implication on employees' wages and this could account for staff turnover. This thus present the contractor with problem of having to recruit new labour force anytime he/she is awarded a contract. This phenomenon impact negatively on the performance and growth of the contractor in the research area, and this is evidence in the $\beta$ value of -0.214 .

Islam et al. (2011) argued that entrepreneurs with business and technical educational background are in a better position to appreciate and analyze hard reality and deal with it intuitively, which seems to play a critical role in entrepreneurial effectiveness. In a developing economy, entreprenuerial skills are needed by SMEs to generate growth and develop new ventures (Mohammed \&Obeleagu-Nzelibe, 2014). In the current study, it has emmerged that the respondents theselves have identified their level of education as a challenge to their growth with GC5 having a $\beta$-value of -0.498 . This indeed has the highest influence on the growth of SMSC amongst all the variables.

\subsection{Lack of government support}

Ofori (1991 and 2012) advocated for a dedicated state agency that will coordinate and regulate construction business in Ghana with view to promoting the interest of indigenous contractors. Laryea (2010) argued that the dominance of expatriate firms in the construction industry in Ghana is detrimental to the growth of indigenous contractors in Ghana. Several studies have indicated that SMEs generally and those in the construction industry in particular are faced with the difficulty of accessing bank and other form of credit and underscored the need for government support in this direction (Osei, 2013; Abor\&Quartey, 2010; Abor\&Biekpeh, 2006; Eyiah\& Cook, 2003). In the current study, lack of government support shows a negative relationship with growth of SMSC with a $\beta$ value of -0.197 . Meaning that growth of SMSC reduces as government withdraws all forms of support for SMSC.

\subsection{Poor Managerial expertise}

Managerial expertise refers to the competency in supervising resources such as human, financial and information which is highly deficient in small scale business owners and accounts for $70 \%$ of business failures in developing countries (Chinomona, 2013; Ucbasaran et al., 2010). According to Frese et al (2007), human, financial and information resources require efficient planning, organizing, implementation and control to be able to offer a sustained competitive edge. Apart from managerial skills, Brinckmann et al (2010) posited that small business owners also need entrepreneurial and marketing skills to spur the growth of businesses which they argued are lacking in small businesses. In the current study respondents have admitted their own deficiencies in managerial 
skills as a bane to their growth. Given the low entry barrier into construction business, it stands to reason that anybody with or without the needed competencies can start a construction business. Characteristic of small businesses, the study revealed that business owners dominate the day to day running of their businesses albeit managerial inadequacies. From the analysis, low managerial expertise shows a negative relationship with the growth of SMSCF with a $\beta$ value of -0.464 . This means that as the managerial expertise of the contractor goes down, the growth of their businesses also goes down. The problem is exacerbated by the difficulty these SMSC face in getting jobs (see table 3.1) which makes it difficult for them to employ and retain people with the requisite skills to help run the business.

\subsection{Absence of politics in contracting}

The study shows that the major clients of respondents in the industry are government of Ghana (GoG) or the District and Municipal assemblies. These projects are often initiated by political office holders who head such relevant agencies. The preliminary interview revealed that that politics take a center stage in the award of contracts. It is the view of respondents that if political influence is removed in the award of contracts it will bring about transparency and a level playing field for contractors and this would translate in to the growth of their businesses. Thus absence of politics in contracting shows a positive relation with growth of SMSC with a positive $\beta$ value of 0.381 . This means that, if all other variables are held constant, absence of politics alone can cause growth of SMSCF by 0.381 units.

\subsection{Upgrading staff}

The respondents identified staff continuous skills training and development as a key growth driver. This factor has significant influence on the growth of SMSCF with a $\beta$ value of 0.300 at $\mathrm{P}<0.05$. This means that, holding all the other predicating variables constant, a unit change in upgrading staff ${ }^{*}$ will result in a standard deviation change of 0.300 in growth of SMSC. Immense benefits accrue to organizations that invest in human capital development (Fugar et al., 2013). Upgrading the skills of employees in the construction industry in particular has the potential of ameliorating the numerous challenges that has bedeviled industry and thus make the industry competitive in the global arena. In this study, SMSCF themselves recognize the importance of improving the skills of their employees. The challenge they may face here is the fact they not get contracts regularly and as such they will not reap the long term benefits in upgrading the skills of their employees.

\subsection{Availability of capital}

The SMSC are of the view that, availability and easy access to capital for their business could be an impetus for the growth of their businesses. Thus from the analysis, availability of capital' has $\beta$ of 0.21 with a $\mathrm{P}<0.05$. This means that availability of capital has a significant influence on the growth of SMSC. However one of the key barriers to rapid growth and development of the SMEs sector is shortage finance (Badu et al., 2014).

\subsection{Comparing with peers}

SMSCF have recognized the importance of comparing their performance to their peers and leaders in the industry in order to stimulate growth. Thus comparing with peers in the industry (GD4)' recorded a $\beta$ value of 0.381 and is significant at $\mathrm{P}<0.05$ (table 4.4 and equation 4.1). The practice of comparing performance against set norms, standards or practice otherwise known in organizational management as benchmarking is necessary for understanding an organization's position relative to other organizations in the same industry and identifying growth opportunities (Maheshwari\& Janssen, 2013; Bannister, 2007). Nasir, et al.(2012) posited that benchmarking is a continuous and systematic process that evaluates the products, services and policies of organizations that are recognized as representing best practices and which serves as a yardstick for organizational improvement. This is consistent with the view of (El-Mashaleh et al., 2007) that benchmarking which is the basis for good construction science helps companies to improve by making changes to their policies and practices and following the path of industry leaders who have demonstrated excellent performance using best industry practices

\subsection{Validation of Model}

Cross validation of findings becomes absolutely mandatory where stepwise option of multiple regression is used for the analysis of data (Field, 2009). According to Field (2009) mathematical applications such as Wherry's or Stein's formulae are used in validation. However, Wherry's equation has the inherent deficiency of being unable to predict a completely new data set. Hence we adopt Stein's equation in this study. In validation, the adjusted $\mathrm{R}^{2}$ is examined. The adjusted $\mathrm{R}^{2}$ give an idea about how much variance in the outcome (growth of SMSC) would be accounted for if the model had been derived from the general population. Thus using the Stein's equation to calculate the adjusted $\mathrm{R}^{2}$ value: 
Stein's formula adjusted $R 2=1-\left[\frac{n-1}{n-k-1} * \frac{n-2}{n-k-2} * \frac{n+1}{n}\right] *(1-R 2)$.

Where, $\mathrm{R}^{2}$ (in bracket)= unadjusted value, $\mathrm{n}=$ number of participants, $\mathrm{K}=$ number of predicator's in the model. Therefore using equation 4.2adjusted

$\mathrm{R}^{2}=1-\left[\frac{101-1}{101-10-1} * \frac{101-2}{101-10-2} * \frac{101+1}{101}\right](1-0.657) \ldots 4.2$

Stein's adjusted $\mathrm{R}^{2}=0.43$ or $43 \%$

Considering the small number of participants as compared to the population, an adjusted $\mathrm{R}^{2}$ value of $40 \%$ is fairly appreciable. The model is fairly rebost indicating the potential of cross validation.

\subsection{CONCLUSIONS}

Forty-eight independent variables were identified from literature and the preliminary inquiry as predicators (independent variables) of the growth of SMSC which is the dependent variable. Of the forty-eight independent variables, ten of them were retained by the regression model that met the minimum criteria for the regression model. The retained variables with their corresponding $\beta$-values are unprofessional conduct of consultants $\left(\mathrm{GC}_{2}\right.$, 0.378), Delayed payment for work done $\left(\mathrm{GC}_{3},-0.403\right)$, High staff turnover $\left(\mathrm{GC}_{4},-0.214\right)$, Low educational level of contractor $\left(\mathrm{GC}_{5},-0.498\right)$, Poor management expertise $\left(\mathrm{GC}_{6}, 0.464\right)$, Absence of politics in contracting $\left(\mathrm{GD}_{1}\right.$, 0.438), Upgrading staff $\left(\mathrm{GD}_{2}, 0.300\right)$, Availability of capital $\left(\mathrm{GD}_{3}, 0.214\right)$, Compare performance with peers in the industry $\left(\mathrm{GD}_{4}, 0.381\right)$. This gives a regression model:

$\mathrm{Y}_{\mathrm{GRW}}=-0.151-0.197 \mathrm{GC}_{1}+0.438 \mathrm{GD}_{1}-0.464 \mathrm{GC}_{6}-0.498 \mathrm{GC}_{5}+0.214 \mathrm{GD}_{3}-0.378 \mathrm{GC}_{2}-0.214 \mathrm{GC}_{4}+$ $0.381 \mathrm{GD}_{4}+0.300 \mathrm{GD}_{2}-0.403 \mathrm{G}$.

The regression model show a validity which can account for $61.9 \%$ of the variance of the growth of SMSC in Ghana and this underscores the robustness of the model for application in the construction industry in Ghana.

SMEs sector in the construction industry have peculiar challenges that are different from SMEs from other industrial sectors. Thus there is the need to establish a public agency that will specifically address the peculiar challenges confronting them. There should be conscious arrangement for SMSCF to learn best practices from market leaders in the industry. In order to spur the needed growth in the businesses of SMSC, the identified growth factors which have negative relationship with growth need to be seriously addressed and those with positive relationship improved.

\section{References}

Abor, J., \& Biekpeh, N. (2006). Small business financing initiatives in Ghana. Problems and perspective in management , 4 (3).

Abor, J., \& Quartey, P. (2010). Issues in SME Development in Ghana and South Africa. International Research Journal of finance and Economics, 39 (6), 215-228.

Acquaah, M., \& Eshun, J. P. (2010). A longitudinal analysis of the moderated effects of networking relationships on organizational performance in a sub-Saharan African economy”. Human Relations , 63 (5), 667-700.

Ahadzie, D. (2007). A model for predicting the performance of project managers in mass house building projects in Ghana, PhD Thesis. Wolverhampton: University of Wolverhampton.

Aigbavboa, C. O., \& Thwala, W. D. (2014). Challenges Facing Black Owned Small and Medium Construction Companies: A Case Study of Nelspruit - Mbombela Municipality, South Africa. Journal of Economics and Behavioral Studies , 6 (10), 771-778.

Ameyaw, C., Mensah, S., \& Osei-Tutu, E. (2013). Curbing corruption in the public procurement process in Ghana. Public policy and administration research, 3(5), 44-53.

Amoah, P., Ahadzie, D. K. \& Ayirebi, D. (2011). The factors affecting construction performance in Ghana: The perspective of small scale building contractors. The Ghana Surveyor; A journal of the Ghana Institution of surveyors , 4 (1), 41-48.

Aniekwu, N. A. (2013). The Politics of the transformation of the construction industry in Africa; proceedings of 2nd applied research conference in Africa. Kumas: ARCA Applied Research Conference in Africa. (ARCA) conference, 25-27 August 2016 (pp. 588-598).

Arokiasamy, A. R. (2013). A Qualitative Study on Causes and Effects of Employee Turnover in the Private Sector in Malaysia. Middle-East Journal of Scientific Research , 16 (11), 1532-151.

Arthur-Aidoo, M. B., Aigbavboa, C. O., \& Thwala, W. D. (2016). Exploring growth gaps among

Artz, G. M., Kim, Y., \& Orazem, P. F. (2016). Does agglomeration matter everywhere? new firm.

Asamoah, R. O., Baiden, B. K., Nani, G., \& Kissi, E. (2019). Review of Exogenous Economic Indicators Influencing Construction Industry. Advances in Civil Engineering, 2019.

Badu, E., Owusu-Manu, D. G., Edwards, D. J., \& Holt, G. D. (2013). Analysis of strategic issues underpinning the 
innovative financing of infrastructure within developing countries. Journal of construction engineering and management, 139(6), 726-737.

Bakar, A. H., Tabassi, A. A., Arman Abd. Razak, A. A., \& Yusof, M. N. (2012). Key Factors Contributing to Growth of Construction Companies: A Malaysian Experience. World Applied Sciences Journal , 19 (9), 1295 1304.

Bannister, F. (2007). The curse of the benchmark: An assessment of the validity and value of e-government comparisons. International Review of Administrative Sciences , 73 (2), 171-188.

Bell, J. (2005). Doing Your Research Project (4th Edition ed.). Buckingham: Open University Press.

Bilau, A. A., Ajagbe, M. A., Sholanke, A. B., \& Sani, T. A. (2015). Impact of Employee Turnover in Small and Medium Construction Firms: A Literature Review. International Journal of Engineering Research \& Technology , 4 (2), 976-984.

Brace, N., Kemp, R., \& Snelgar, R. (2009). SPSS for Psychologists, A Guide to Data Analysis Using SPSS for Windows (3rd Edition ed.). Hamshire: Palgrave Machmillan .

Brinckmann, J., Grichnik, D., \& Kapsa, D. (2010). Should entrepreneurs plan or just storm the castle? A metaanalysis on contextual factors impacting the business planning-performance relationship in small firms, . Journal of Business Venturing. , 25, 244-40.

Burns, N., \& Grove, K. S. (1997). The Practice of Nursing Research Conduct, Critique, \& Utilization. Philadelphia.: W.B. Saunders and Co.,.

Chinomona, R. (2013). Business Owner's Expertise, Employee Skills Training And Business Performance:A Small Business Perspective. The Journal of Applied Business Research , 29 (6), 1883-1896.

Choi, J., Goldschlag, N., Haltiwanger, J., \& Kim, J. D. (2019). The Post Entry Growth and Survival of Business Startups: The Role of Founding Teams. Unpublished Manuscript.

Coleman, S., Cotei, C., \& Farhat, J. (2016). The debt-equity financing decisions of US startup firms. Journal of Economics and Finance, 40(1), 105-126.

Creswell, J. W. (2007). Qualitative inquiry and research design: Choosing among five approaches (3rd Edition ed.). Thousand Oaks: CA: Sage.

Damoah, O. B. (2013). Strategic factors and firm performance in an emerging economy. African Journal of Economic and Management Studies , 4 (2), 267-287.

El-Mashaleh, M. S., Minchin, R. E., \& O’Brien, W. J. (2007). Management of construction firm using benchmarking. Journal of Management Engineering , 23 (1), 10-17.

Eyiah, A. (2004). Regulation, and Small contractor development: A case of Ghana . Manchester: Centre on regulation and competition

Eyiah, A., \& Cook, P. (2003). Financing small and medium scale contractors in developing countries; A Ghana case study. Journal of construction managment and economcs , 21 (4), 357-367.

Field, A. (2009). Discovering Statistes Using SPSS (3rd Edition ed.). London: SAGE Publications Ltd.

Frese, M., Krauss, S. I., Keith, N., Escher, S., \& Friedrich, C. (2007). Business owners' action planning and its relationship to business success in three African countries. Journal of Applied Psychology , 92 (6), 14811496.

Fugar, F., Ashiboe-Mensah, N., \& Adinyira, E. (2013). Human Capital Theory: Implications for the Ghanaian Construction Industry Development. Journal of Construction Project Management and Innovation, 3 (1), 464 479.

Geroski, P. A. (1999). The Growth of Firms in Theory and in Practice, Discussion Paper No. 9092. Centre for Economic Policy Research , 1-30.

Gupta, P. D., Guha, S., \& Krishnaswami, S. S. (2013). Firm growth and its determinants. Journal of innovation and entreprenuership , 2 (15), 1-14.

Hove, G. (2016). Small scale contractors in Africa's emerging markets: The case of South Africa.

Insah, B., Mumuni, A. I., \& Bangniyel, P. (2013). An Analysis of the Determinants of business growth in Ghana: A study of Wa Municipal in the Upper West Region. European Journal of Business and Management , 31 , 5

Islam, A., Khan, M. A., \& Obaidullah, A. Z. (2011). Effect of Entrepreneur and Firm Characteristics on the Business Success of Small and Medium Enterprises (SMEs) in Bangladesh. International Journal of Business and Management , 6 (3), 289-299.

Jaafaar, M., \& Abdul-Aziz, A.-R. (2005). Resource based view and critical success factors:A study on small and medium sized contrcting enterprises(SMCEs) in Malaysia. The International Journal of Construction Management, 61-77.

Jaccard, J. J., \& Turrisi, R. (2003). Interaction Effects in Multiple Regression (Quantitative Applications in the Social Sciences). Sage Publications Inc.

Kish, L. (1965). Survey Sampling. New York: John walley and Sons Inc.

Kissi, E., Sadick, M. A., \& Agyemang, D. Y. (2018). Drivers militating against the pricing of sustainable construction materials: The Ghanaian quantity surveyors perspective. Case studies in construction materials, 


\section{$8,507-516$.}

Kulemeka, P. J., Kululanga, G., \& Morton, D. (2015). Critical Factors Inhibiting Performance of Small- and Medium-Scale Contractors in Sub-Saharan Region: A Case for Malawi. Journal of Construction Engineering.

Kuria, S., Alice, O., \& Wanderi, P. M. (2012). Assessment of Causes of Labour Turnover in Three and Five StarRated Hotels in Kenya. International Journal of Business and Social Science , 3 (15), 311-317.

Laryea, S. (2010). Challenges and Opportunities Facing Contractors in Ghana. Accra: West African Built Environment Research (WABER).

Leedy, P. D., \& Jeanne, E. O. (2005). Practical research, planning and design (8th Edition ed.). New Jersey: Pearson Prentice Hall.

Linneman, T. J. (2010). Social Statistics: The Basics and Beyond. Rouledge, Taylor and Francis Group. Location decisions in rural and urban markets. Journal of Regional Science, 56(1), 72-95.

Maheshwari, D., \& Janssen, M. (2013). Measurement and benchmarking foundations: Providing support to organizations in their development and growth using dashboards. Government information quarterly , 30, S83-S93.

Mohammed, U. D., \& Obeleagu-Nzelibe, C. G. (2014). Entrepreneurial Skills and Profitability of Small and Medium Enterprises (Smes): Resource Acquisition Strategies for New Ventures in Nigeria, Proceedings of 25th International Business Research Conference. Taj Hotel, Cape Town, South Africa.

Nasir, H., Haas, C. T., Rankin, J. H., Fayek, A. R., Forgues, D., \& Ruwanpura, J. (2012). Development and implementation of a benchmarking and metrics program for construction performance and productivity improvement. Can. J. Civ. Eng. , 39, 957-967.

Nawaz, T., \& Ikram, A. A. (2013). Unethical Practices in Pakistani Construction Industry. European Journal of Business and Management , 5 (4), 188-204.

Obeng, B. A., Robson, P., \& Haugh, H. (2014). Strategic entrepreneurship and small firm growth in Ghana. International Small Business Journal, 32(5), 501-524.

Ofori, G. (1991). Programmes for improving the performance of contracting firms in developing countries:A review of sapproaches and appropriate optons. Construction Msnsgement and Economics , 9, 19-38.

Ofori, G. (2000). Growth paths of construction enterprises in Singapore, 1980-98. Engineering, Construction and Architectural Management , 7 (3), 307-321.

Ofori, G. (2012). Developing the Construction Industry in Ghana: the case for a central agency. Accra: unpublished.

Osei, V. (2013). The construction industry and its linkages to the Ghanaian economy-polices to improve the sector's performance. International Journal of Development and Economic Sustainability, 1(1), 56-72.

Penrose, E. (1959). The theory ofthe growth ofthe firm. JohnW iley\& Sons, New York. Preprints, 2017070091. doi: 10.20944/preprints201707.0091.v1) prerequisite for success of the construction industry development Agenda In: Proceedings $5^{\text {th }}$

Ucbasaran, D., Westhead, P., Wright, M., \& Flores, M. (2010). The nature of entrepreneurial experience,business failure and comparative optimism . Journal of Business Venturing, 25, 541-555. , 25, 541-555.

Windapo, A. (2017). Determinants of the sustainability and growth of construction contractors.

Yankah, J. E., Aigbavboa, C. O., \& Thwala, W. D. (2016). Marketing management as a potential prerequisite for success of the construction industry development Agenda.

Muogbo, U. S. (2013). The Impact of Strategic Human Resource Management on Small and Medium Sized Enterprises (A Study of some Selected Paint Manufacturing Firms in Anambra State Nigeria). Global Journal of Management and Business Studies. , 3 (3), 323-340. 